Original Research Article

\title{
Antipsychotics in schizophrenia: a retrospective study of drug utilization pattern in outpatient department of psychiatry at a tertiary care hospital
}

\author{
Usharani H Patted ${ }^{1}$, Hema N.G. ${ }^{1 *}$, Anil Kumar Mysore Nagaraj²
}

\begin{abstract}
${ }^{1}$ Department of Pharmacology, Mysore Medical College and Research Institute, Mysore, Karnataka, India

${ }^{2}$ Department of Psychiatry, K.R Hospital, Mysore Medical College and Research Institute, Mysore, Karnataka, India
\end{abstract}

Received: 15 November 2017 Accepted: 04 December 2017

*Correspondence to:

Dr. Hema N.G.,

Email: dr.hema_ng@yahoo.com

Copyright: (C) the author(s), publisher and licensee Medip Academy. This is an openaccess article distributed under the terms of the Creative Commons Attribution NonCommercial License, which permits unrestricted noncommercial use, distribution, and reproduction in any medium, provided the original work is properly cited.

\begin{abstract}
Background: Psychiatric disorders are one of the major causes of morbidity and the burden of illness is enormous and remains grossly under represented. Psychotropic drugs have had a remarkable impact in psychiatric practice. Currently a large number of atypical antipsychotics available in the market are endorsed as better options for treating schizophrenia than the typical antipsychotics. The main objective of the study was to find the commonly prescribed antipsychotics in schizophrenia patients in a tertiary care center.

Methods: After Institutional Ethics Committee approval, a retrospective crosssectional drug utilization study of 400 prescriptions was under taken from 1st July 2015 to $30^{\text {th }}$ July 2016 in the outpatient department of psychiatry of a tertiary care hospital. The prescribing pattern of antipsychotics in schizophrenia patients $(\mathrm{N}=107)$ was measured.

Results: Out of 400 cases in the outpatient department, schizophrenia cases were predominant $(\mathrm{N}=107$ i.e. $27 \%$ ) out of which $42.1 \%$ were females and $57.9 \%$ were males. This was followed by mood disorders and neurotic \& somatoform disorders. The most common antipsychotic used was olanzapine followed by risperidone. Least commonly used antipsychotic was haloperidol. Most of the patients who received risperidone also received an anticholinergic trihexyphenidyl (91.8\%).

Conclusions: Olanzapine and risperidone are the most commonly used antipsychotics. Anticholinergics should be used only in selected patients on antipsychotics as tolerance develops to extrapyramidal side effects. Anticholinergics are unnecessary after 3-6 months in all except $10 \%$ of patients. Moreover, it has its own side effects and adversely interacts with antipsychotics.
\end{abstract}

Keywords: Antipsychotics, Drug utilization study, Outpatients, Psychiatry

\section{INTRODUCTION}

Schizophrenia is a severe psychiatric disorder that has immense impact on the individual and the society. ${ }^{1}$ Schizophrenia affects 21 million people worldwide and its prevalence in India is 4.3 to 8.7 million. ${ }^{2,3}$ Schizophrenia is characterized by positive symptoms (delusions, hallucinations), negative symptoms (amotivation, poverty of speech, social withdrawal) and cognitive impairment. ${ }^{1}$

Mainstay of treatment for schizophrenia are antipsychotics. Conventional antipsychotics like chlorpromazine, haloperidol use often leads to acute and chronic extrapyramidal side effects (e.g. tremors, rigidity, tardive dyskinesia). Second generation antipsychotics like olanzapine, risperidone, aripiprazole, amisulpride are commonly used now as they infrequently induce the extrapyramidal side effects and are beneficial in improving negative symptoms of schizophrenia. ${ }^{4}$

Drug utilization study has been defined by the World Health Organization (WHO) as "The marketing, distribution, prescription and uses of drugs in a society with special emphasis on the resulting medical, social and 
economical consequences." The principle aim of the drug utilization research is to facilitate the rational use of the drugs. Without the knowledge of how the drugs are being prescribed, it is difficult to suggest the measures to improve prescribing habits. ${ }^{5}$

Retrospective drug utilization review can be used to identify problems in prescribing patterns through the analysis and interpretation of aggregate archival data on drug prescriptions. This process has no immediate effect on patient care but can identify trends and prompt interventions. ${ }^{6}$ Therefore, the present study will be carried out to understand and evaluate the prescription pattern of medications in Department of Psychiatry of a tertiary care hospital.

Objectives of the study was to analyse the drug utilization pattern and to determine the rationality of prescriptions in outpatient department of Psychiatry.

\section{METHODS}

After obtaining Institutional Ethical Committee approval, prescriptions of all the patients attending psychiatry outpatient department are included in the study. Demographic data such as subject's initials, age, gender, and also diagnosis, complete prescription is recorded in the proforma from the computer data.

\section{Inclusion criteria}

Prescription of all the patients attending psychiatry outpatient department.

\section{Exclusion criteria}

In-patients, referred patients, were excluded from the study:

Analysis of rationality of prescription using WHO Core prescribing indicators. ${ }^{7}$

- Average number of the drugs per prescription.

- Average number of the antipsychotic drugs per prescription.

- Percentage of the antipsychotic drugs prescribed by generic name.

- Percentage of injectable drugs prescribed.

- Percentage of the antipsychotic drugs prescribed from essential drug list.

\section{Study design}

An observational retrospective cross-sectional study was conducted for one year duration i.e., from $1^{\text {st }}$ July 2015 to $30^{\text {th }}$ July 2016 in psychiatry outpatient department of K.R hospital, Mysore.

\section{Sample size}

The number of patients attending outpatient department of psychiatry over a month was approximately 1600. Based on this, the estimated sample size is approximately 400 by using the formula $\mathrm{n}=4 \mathrm{pq} / \mathrm{d}^{2}$

\section{Statistical analysis}

The data in this study will be analysed using descriptive statistics, mean, standard deviation, frequency, percentages, chi square test and Cramer's $\mathrm{V}$ test.

\section{RESULTS}

\section{Demographic background of schizophrenia patients}

Out of 400 cases in the outpatient department, Schizophrenia patients were 107. Schizophrenia was more found in patients $<40$ years of age accounting for $70 \%$; $30 \%$ schizophrenic patients were $>40$ years of age. The average age of schizophrenics was 35.6 years. The percentage of male and female patients was $57.9 \%$ and $42.1 \%$ respectively (Figure 1, Figure 2).

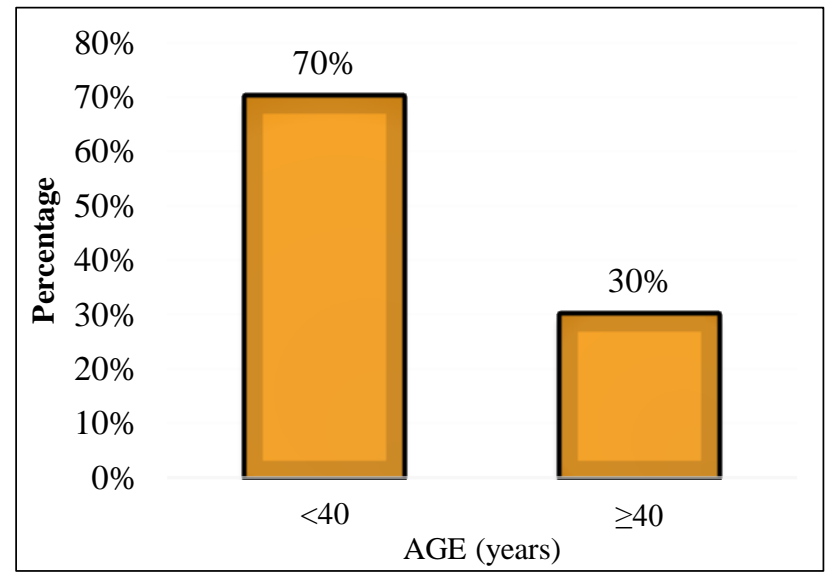

Figure 1: Age distribution of schizophrenia patients.

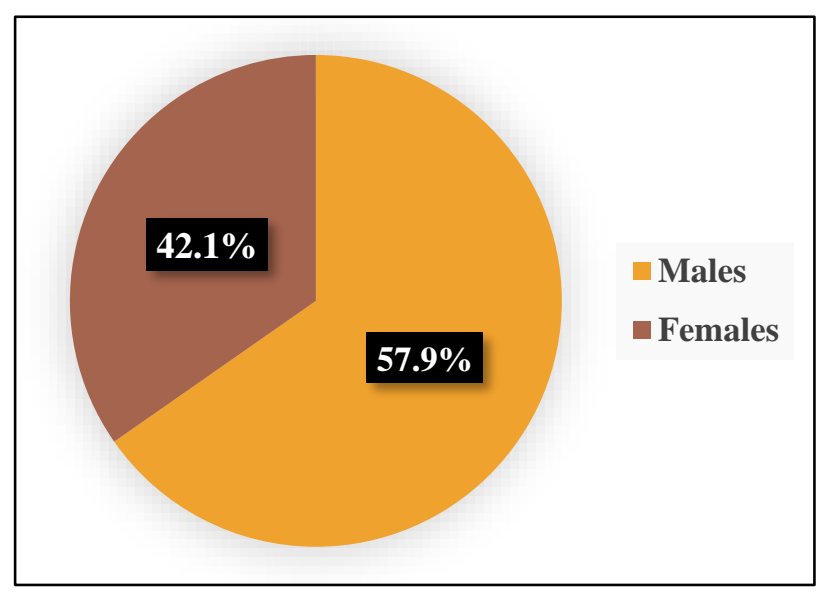

Figure 2: Gender distribution of schizophrenia patients. 


\section{Schizophrenia and antipsychotic drugs}

Olanzapine was the commonest antipsychotic drug prescribed $-43.55 \%$, followed by risperidone $37.4 \%$, fluphenazine $9.9 \%$, amisulpride $3.05 \%$, chlorpromazine and penfluridol $2.29 \%$, flupentixol $1.53 \%$ and the least used was haloperidol $0.76 \%$ (Figure 3, Figure 4).

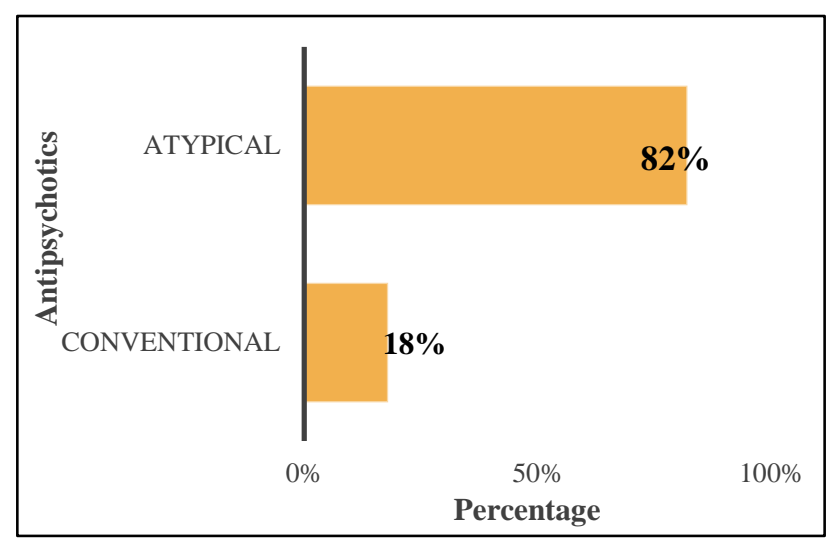

Figure 3: Conventional and atypical antipsychotics use.

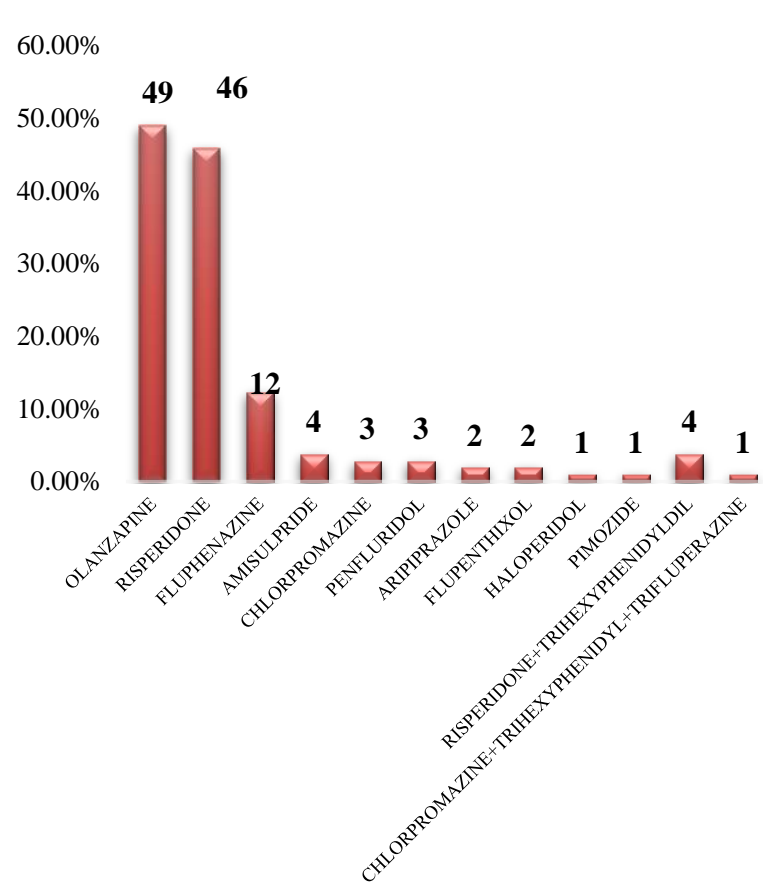

Figure 4: Percent utilization of antipsychotics in schizophrenia patients.

Fixed dose combinations used were olanzapine + fluoxetine $5.6 \%$ and risperidone + trihexyphenidyl $3.7 \%$.

Analysis of prescription pattern according to WHO drug use indicators

The $\mathrm{N}=107$ prescriptions contained 287 drugs. Out of these 131 were antipsychotic drugs. Average number of drugs per prescription was 2.68. Average number of antipsychotics per prescription was $1.2 .47 .33 \%$ patients received antipsychotics which were in the National list of medicines 2015. Data indicated that $56.45 \%$ schizophrenic patients received antipsychotics by generic name and $43.55 \%$ received antipsychotics by trade name. $47.33 \%$ patients received antipsychotics which were in the National list of essential medicines 2015 (Table 1).

Table 1: WHO Prescribing indicators.

\begin{tabular}{|ll|}
\hline Who prescribing indicators \\
\hline Average number of drugs per prescription & 2.7 \\
\hline $\begin{array}{l}\text { Average number of antipsychotics } \\
\text { /prescription in schizophrenic patients }\end{array}$ & 1.2 \\
\hline $\begin{array}{l}\text { Percentage of drugs prescribed by generic } \\
\text { name }\end{array}$ & $56.4 \%$ \\
\hline $\begin{array}{l}\text { Percentage of drugs prescribed from } \\
\text { National list of essential medicines } 2015\end{array}$ & $21.6 \%$ \\
\hline $\begin{array}{l}\text { Percentage of encounters with the } \\
\text { prescribed injection }\end{array}$ & $8.4 \%$ \\
\hline
\end{tabular}

Other drugs used in schizophrenia

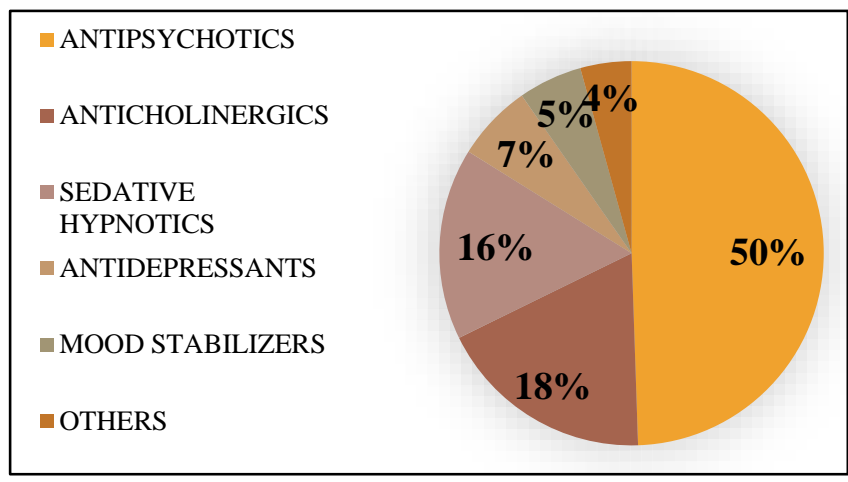

Figure 5: Frequency of use of different class of drugs.

The other drugs commonly co-prescribed were multivitamins, benzodiazepines like lorazepam and antidepressants like fluoxetine, anticholinergics like trihexyphenidyl and mood stabilizers like lithium (Figure $5)$.

Pattern of antipsychotic drug use as per ATC/DDD classification (Table 2).

Table 2: ATC/DDD classification of more frequently used antipsychotics in schizophrenia.

\begin{tabular}{|lllll|}
\hline Drug & ATC & $\begin{array}{l}\text { DDD } \\
(\mathbf{m g})\end{array}$ & $\begin{array}{l}\text { PDD } \\
(\mathbf{m g})\end{array}$ & PDD/DDD \\
\hline Olanzapine & N05AH03 & 10 & 9.47 & 0.95 \\
\hline Risperidone & N05AX08 & 8 & 4.18 & 0.52 \\
\hline Amisulpride & N05AL05 & 400 & 87.5 & 0.21 \\
\hline Chlorpromazine & N05AA01 & 300 & 66.67 & 0.22 \\
\hline Penfluridol & N05AG03 & 3.3 & 3.3 & 1 \\
\hline Aripiprazole & N05AX12 & 15 & 6.25 & 0.41 \\
\hline Trifluperazine & N05AB06 & 20 & 5 & 0.25 \\
\hline Pimozide & N05AG02 & 4 & 2 & 0.5 \\
\hline
\end{tabular}


DDDs mentioned in the table are of oral route. The ATC/DDD classification is obtained from WHO ATC/DDD website 2017.

\section{DISCUSSION}

The burden of illness resulting from psychiatric and behavioural disorders is enormous. ${ }^{7}$ Several observational studies nationally and internationally have analysed the pattern of psychotropic drugs prescribed in hospital inpatient or outpatient settings. Trends towards prescribing multiple, new costly drugs, prescribing in children, women, old (low dose) and off label use are increasing. ${ }^{6}$

Drug utilization studies seek to monitor, evaluate and if necessary, suggest modifications in prescribing patterns so as to make medical care rational and cost-effective. It is important to realize that inappropriate use of drugs represent a potential hazard to patients and an unnecessary expense. This necessitates a periodic review of pattern of drug utilization to ensure safe and effective treatment. ${ }^{7}$

\section{Demographic details and schizophrenia}

In the course of research, it was noticed that out of 107 cases of schizophrenia, $57.9 \%$ were males and $42.1 \%$ were females. Our result was similar to the study conducted by Banerjee et.al where $58.76 \%$ of males and $41.24 \%$ of females suffered from schizophrenia. ${ }^{8}$ Our results were also similar to a multicentric study, conducted by MY Chong et.al where male predominance was consistent accounting for $55.9 \%$ of cases. ${ }^{9}$

Most of the schizophrenics were <40years (70\%) and the average age was 35.6 years. Similar results were seen with a study conducted by Banerjee et.al where $78.6 \%$ were $<40$ years and $21.4 \%$ were $>40$ years. ${ }^{8}$ But different results were observed by the study conducted in Japan by $\mathrm{S}$ Cheung et.al, where the average age of patients suffering with schizophrenia was 61.9 years. ${ }^{10}$

\section{Drug utilization of Schizophrenia}

\section{Drug therapy}

Average number of drugs per prescription was 2.68 which was similar to study conducted by Paul et.al and Rode SB et.al with average drug per prescription being 2.2 and 2.1 respectively. ${ }^{11,12}$ Our average drug per prescription was slightly higher than study conducted by Karan B Thakkar et.al which showed 1.7 drugs per prescription. ${ }^{13}$ Drugs per prescription in our study is slightly higher than the optimal value according to Atif et.al. i.e. 1.6-1.8. ${ }^{14}$

Maximum drugs prescribed per patient was 5 and was prescribed to only 2 patients which indicates that polypharmacy was less seen in our observational study. Similar observation was made by Karan B Thakkar et.al. ${ }^{12}$

\section{Observed drug use pattern of antipsychotics}

Average number of antipsychotics per prescription was 1.2 and maximum antipsychotics prescribed was 3 in just one patient.

The common antipsychotics used was olanzapine $48.6 \%$ followed by risperidone $45.8 \%$. Atypical antipsychotics $(82 \%)$ were more used than conventional antipsychotics (18\%). This pattern of drug use may be because, olanzapine and risperidone are supplied free of cost and atypical antipsychotics are known to have less extrapyramidal side effects plus they improve the negative symptoms better when compared to conventional antipsychotics. Similar observations were made by Rode SB et.al., where $65.34 \%$ patients received atypical antipsychotics and olanzapine (45.13\%) was the most common antipsychotic prescribed. ${ }^{12}$ Paul et.al study also showed that olanzapine $(51.04 \%)$ was most commonly prescribed followed by risperidone $(17.14 \%){ }^{11}$

$47.33 \%$ patients received antipsychotics which were in the National list of essential medicines (NLEM) 2015 which is better than Banerjee et.al. study which used only drugs from NLEM list in only $28.6 \%$ schizophrenia patients. ${ }^{8}$ Though olanzapine was used more in our study, it is not included in the NLEM 2015 of India.

Fixed dose combinations (FDC) were used less, contributing to only $27 \%$. This may be because fixed dose combinations are not freely available in our hospital. The most common FDC used was olanzapine + fluoxetine followed by risperidone + trihexyphenidyl accounting for $5.6 \%$ and $3.7 \%$ respectively. Rode SB et.al. study also showed only $20 \%$ use of FDCs. ${ }^{12}$ Fluoxetine might have been prescribed in combination with olanzapine in order to counteract the co-morbid depression. Trihexyphenidyl in combination with risperidone prevents extrapyramidal side effects.

Depot injections of flupentixol and fluphenazine were used which contributed to $8.4 \%$. Parenteral use of drugs was only $5.01 \%$ in a study by Paul et.al. ${ }^{10}$ Depot preparations help to manage the non-adherence of the patients. ${ }^{15}$

Schizophrenia patients in our study received drugs other than antipsychotics, which included anticholinergics like trihexyphenidyl, antidepressants like fluoxetine, sedative hypnotics like lorazepam and others like multivitamins. Sedative hypnotics might have been used to control the agitation or anxiety of the patient and fluoxetine in schizophrenic patients with co-morbid depression. ${ }^{16}$ In our study, co-prescription of trihexyphenidyl (anticholinergic) with risperidone was $92 \%$. Anticholinergics in schizophrenia is usually prescribed to treat antipsychotic induced extra pyramidal side effects (EPSEs). On development of EPSE, the dose of antipsychotic is reduced, or the antipsychotic is switched to another antipsychotic. ${ }^{16}$ 
Current treatment guidelines do not recommend prophylactic and long-term use of anticholinergics in schizophrenia patients who are on antipsychotics. ${ }^{17}$ Anticholinergics should be used only in selected patients who are on high potency antipsychotics like haloperidol or have a history of EPSE or has developed EPSE and there is no improvement even after switching the antipsychotic. Anticholinergics should be administered for short duration like 3-6 months. ${ }^{18}$ Anti-cholinergic have their own side effects like dry mouth, urinary disturbances, constipation, cognitive impairment, worsening of tardive dyskinesia and adversely interact with antipsychotics. ${ }^{19}$

Our study limits us to comment on the rationality of coprescription of trihexyphenidyl, as ours was a retrospective study and could not speculate whether trihexyphenidyl was prescribed during first contact of the patient or after the appearance of extrapyramidal side effects, nor can we comment on the duration of trihexyphenidyl being consumed.

Since ours was a retrospective study, we could not evaluate factors such as patient compliance and adverse drug reactions. Our study provides the baseline data and would help build data for carrying out further drug utilization studies.

\section{ACKNOWLEDGEMENTS}

Authors would like to thank whole Psychiatry and Pharmacology department for the co-operation. We would also like to thank patients whose case records were used for the study.

\section{Funding: No funding sources}

Conflict of interest: None declared

Ethical approval: The study was approved by the Institutional Ethics Committee

\section{REFERENCES}

1. Owen MJ, Sawa A, Mortensen PB. Schizophrenia. Lancet. 2016;388(10039):86-97.

2. Schizophrenia. In: WHO, 2017. Available at: http://www.who.int/mental_health/management/schiz ophrenia/en/s. Accessed 29 October 2017.

3. Schizophrenia facts and statistics. 2017. Available at: http://www.schizophrenia.com/szfacts.htm. Accessed 29 October 2017.

4. Berger A, Edelsberg J, Sanders KN, Alvir JMJ, Mychaskiw MA. Medication adherence and utilization in parents with schizophrenia or bipolar disorder receiving aripiprazole, quetiapine or ziprasidone at hospital discharge: A retrospective cohort study. BMC Psychiatry. 2012;12:99.

5. Piparva KG, Parmar DM, Singh AP, Gajera MV, Trivedi HR. Drug utilization study of psychotropic drugs in outdoor patients in a teaching hospital. Indian J Psychol Med. 2011;33(1):54-8.
6. Deshmukh SA, Shaikh TS. Evaluation of psychotropic drugs use pattern among out patients attending psychiatry department at government medical college and hospital, Nagpur: A cross sectional study. Int J Pharm Bio Sci. 2012;3(3):428-36.

7. Rode SB, Ajagallay RK, Salankar HV, Sinha U. A study on drug prescribing pattern in psychiatry outpatient department from a tertiary care teaching hospital. Int J Basic Clin Pharmacol. 2014;3(3):51722.

8. Banerjee I, Roy B, Sathian B, Banerjee I, Chakraborthy PK, Saha A. Sociodemographic profile and utilization pattern of antipsychotic drugs among schizophrenic inpatients: a cross sectional study from western region of Nepal. BMC Psychiatry. 2013;13:96.

9. Chong MY, Tan CH, Fujii S, Ungyari GS, Si T, Chung EK, et al. Antipsychotic drug prescription for schizophrenia in East Asia: rationale for change. Psychiatry Clin Neurosci. 2004;58(1):61-7.

10. Cheung S, Hamuro Y, Mahlich J, Nakahara T, Sruamsiri R, Tsukazawa S. Drug utilization of Japanese patients diagnosed with schizophrenia: An administrative database analysis. Clin Drug Investig. 2017;37(6):559-69.

11. Paul PK, Konwar M, Das S. To study the prescribing pattern of antipsychotic drugs in a tertiary care hospital of Assam. Int $\mathbf{J}$ Pharm Pharm Sci. 2014;6(4):435-7.

12. Rode SB, Ajagallay RK, Salankar HV, Sinha U. A study on drug prescribing pattern in psychiatry outpatient department from a tertiary care teaching hospital. Int J Basic Clin Pharmacol. 2014;3(3):51722.

13. Thakkar KB, Jain MM, Billa G, Joshi A, Khobragade AA. A drug utilization study of psychotropic drugs prescribed in the psychiatry outpatient department of a tertiary care hospital. J Clinic Diag Res. 2013;7(12):2759-64.

14. Atif M, Sarwar MR, Azeem M, Umer D, Rauf A, Rasool A, et al. Assessment of WHO/INRUD core drug use indicators in two tertiary care hospitals of Bahawalpur, Punjab, Pakistan. J Pharma Policy Practice. 2016;9:27.

15. West JC, Marcus SC, Wilk Joshua, Countis LM, Regier DA, Olfson M. Use of depot antipsychotic medications for medication nonadherence in schizophrenia. Schizophrenia Bulletin. 2008;34(5):995-1001.

16. Practice guidelines for the treatment of patients with schizophrenia, 2004. Available at: http://psychiatryonline.org/pb/assets/raw/sitewide/pra ctice_guidelines/guidelines/schizophrenia.pdf. Accessed 27 October 2017.

17. Role of anticholinergic medications in patients requiring long-term antipsychotic treatment for psychotic disorders, 2012. Available at: http://www.who.int/mental_health/mhgap/evidence/r esource/psychosis_q6.pdf?ua=1. Accessed 27 October 2017. 
18. Chakrabarti S, Kulhara P. Clinical practice guidelines for the management of schizophrenia. Indian $\mathrm{J}$ Psychiatry. 2017;59(1):19-33.

19. Ogino S, Miyamoto S, Miyake N, Yamaguchi N. Benefits and limits of anticholinergic use in schizophrenic use in schizophrenia: focusing on its effect on cognitive function. Psychiatry Clin Neurosci. 2014;68(1):37-49.
Cite this article as: Patted UH, Hema NG, Nagaraj AKM. Antipsychotics in schizophrenia: a retrospective study of drug utilization pattern in outpatient department of psychiatry at a tertiary care hospital. Int J Basic Clin Pharmacol 2018;7:167-72. 